\title{
LEVANTAMENTO DE ESPÉCIES VEGETAIS E UTILIZAÇÃO EM QUINTAL AGROFLORESTAL DE ESTABELECIMENTO AGRÍCOLA NO ASSENTAMENTO ALEGRIA - MARABÁ, PARÁ
}

\author{
Thiago Paixão da Silva ${ }^{1}$; Erica Micaelli de Jesus Silva²; Ismael Alves Amorim³; \\ Alyssandra Lima Aquino*; Thaís Esllem da Silva Matos; ${ }^{5}$ Diego Macedo Rodrigues ${ }^{6}$. \\ ${ }^{1}$ Graduando em Agronomia, Faculdade de Ciências Agrárias de Marabá (FCAM), Universidade Federal do Sul e \\ Sudeste do Pará (UNIFESSPA). Marabá, Pará, Brasil. thiagro14@ hotmail.com \\ ${ }^{2}$ Graduanda em Agronomia da FCAM, UNIFESSPA. Marabá, Pará, Brasil. erica_micaelli@ hotmail.com \\ ${ }^{3}$ Graduando em Agronomia da FCAM, UNIFESSPA. Marabá, Pará, Brasil, ismaelamorim93@ gmail.com \\ ${ }^{4}$ Graduando em Agronomia da FCAM, UNIFESSPA. Marabá, Pará, Brasil. alyssandra.agro@ hotmail.com \\ ${ }^{5}$ Graduando em Agronomia da FCAM, UNIFESSPA. Marabá, Pará, Brasil. thais.esllenn@ hotmail.com \\ ${ }^{6}$ Professor, Mestre da FCAM, UNIFESSPA. Marabá, Pará, Brasil. diegomacedo@ufpa.br.
}

RESUMO: O objetivo deste trabalho foi realizar o levantamento de espécies vegetais e seus respectivos usos pelo agricultor no quintal agroflorestal de um estabelecimento agrícola familiar no Assentamento Alegria, Marabá - PA. O levantamento foi realizado através da identificação das principais espécies vegetais em quintal agroflorestal de aproximadamente 1 ha. Foram coletadas partes dos vegetais para confecção de exsicatas e o registro dos seus usos foi realizado pelo relato dos agricultores. As espécies vegetais presentes no quintal agroflorestal contribuem tanto para a manutenção ecológica e para a renda obtida pela comercialização de frutos no próprio assentamento. As frutíferas representaram a maior quantidade de plantas presentes no quintal agroflorestal.

PALAVRAS-CHAVE: Agricultura familiar. Frutíferas. Sistema agroflorestal.

\section{SURVEY OF PLANT SPECIES AND THEIR USES IN HOMEGARDEN OF AGRICULTURAL ESTABLISHMENT IN SETTLEMENT JOY - MARABÁ, PARÁ}

\begin{abstract}
The objective of this study was to conduct a survey of plant species and their uses by farmers in homegarden of a family farm property in the Settlement Joy, Maraba - PA. The survey was conducted by identifying the major plant species in agroforestry yard of approximately 1 ha. Parts of the plant were collected for preparation of herbarium specimens and the record of its uses was conducted by the account of farmers. The plant species present in homegarden contribute to ecological maintenance and proceeds from the sale of fruit in both the settlement itself. The fruit accounted for the largest amount of plants present in homegarden.
\end{abstract}

KEYWORDS: Agroforestry system. Family farm. Fruitful.

\section{ESTUDIO DE VEGETALES Y USO EN HUERTA AGROFORESTAL DE ESTABLECIMIENTO AGRÍCOLA EN ASENTAMIENTO ALEGRÍA - MARABÁ, PARÁ}

RESUMEN: El objetivo de este estudio fue realizar un estudio de las especies de plantas y sus usos por los agricultores en la huerta agroforestal de un negocio familiae en el 
Asentamiento Alegría, Maraba - PA. La encuesta se llevó a cabo mediante la identificación de las principales especies de plantas en el patio agroforestal de aproximadamente 1 ha. Partes de la planta se recogieron para la preparación de especímenes de herbario y el registro de sus usos se llevó a cabo por la cuenta de los agricultores. Las especies de plantas presentes en el huerto contribuyen al mantenimiento y procede ecológica de la venta de fruta, tanto en el propio asentamiento. Las frutiferas representaran la mayor cantidad de plantas presentes en el huerto agroforestal.

PALABRAS-CLAVE: Agricultura familiar. Cultivo de frutas. Sistema agroforestal.

A utilização de plantas das mais variadas espécies para fins medicinais, culinários, ornamentais e outros se tornou cada vez mais comum entre povos de várias culturas ao longo do tempo. Agricultores familiares associam diversas espécies vegetais como frutíferas e hortaliças em seus quintais agroflorestais com o objetivo de obter frutos para consumo próprio, e para comercialização, ou partes da planta como a folha e raiz para uso medicinal.

No quintal agroflorestal, além da atividade da criação de pequenos animais, ao redor da residência, é cultivada uma ampla variedade de espécies de plantas, dentre elas, às aromáticas, condimentares, florestais e ornamentais (CASTRO et al., 2009).

Além do consumo familiar, as plantas condimentares e aromáticas contribuem para a diversificação e geração de renda, pela comercialização da produção excedente. Dessa forma, tornam-se um fator de complementação da renda dos pequenos agricultores rurais da região
Amazônica. O cultivo de diferentes espécies vegetais no quintal agroflorestal favorece a biodiversidade local contribuindo com a manutenção do equilíbrio entre as populações (FRAXES, 2011).

O objetivo deste trabalho foi realizar o levantamento de espécies vegetais e seus respectivos usos pelo agricultor no quintal agroflorestal de um estabelecimento agrícola.

O levantamento foi realizado no quintal agroflorestal de aproximadamente 1 ha em um estabelecimento agrícola no Assentamento Alegria Marabá - PA.

A metodologia baseou-se na observação ocular das plantas presentes no quintal e também através de entrevista com os agricultores, bem como informações colhidas em conversas informais com os mesmos, buscou-se observar todas as espécies presentes no quintal agroflorestal, a família foi questionada quanto ao uso de todas as espécies vegetais no quintal agroflorestal. Posteriormente as espécies observadas foram classificadas quanto a 
seu nome científico conforme literatura atualizada.

Foram elaboradas seis categorias referentes ao potencial de uso das plantas pelos agricultores, que são: frutíferas, medicinais, cultivar, hortaliças, ornamentais e madeireiras. Por meio das informações obtidas foi possível identificar as espécies consideradas mais importantes pela família e suas principais formas de uso.

Foi recolhido material vegetal das plantas de maior relevância econômica para os agricultores, foram coletados folhas ou ramos livres de injúrias ou doenças das espécies economicamente importantes para a família.

Após a coleta deste material foram confeccionadas exsicatas, onde utilizou-se duas prensas de madeira, duas cordas para prender as prensas, folhas de jornal para montar as partes vegetais e duas fichas de coleta de campo para identificação e datação da coleta das espécies, as partes vegetais coletadas foram dispostas nas folhas de jornal e logo após estas folhas foram fechadas com cuidado sobre a parte vegetal, em seguida colocou-se a parte da planta recolhida na prensa de madeira, cada espécie em uma prensa separada e posteriormente foram amarradas com as cordas.

Logo após o processo de confecção as exsicatas foram depositadas no herbário da
Universidade Federal do Pará no Campus II, em Marabá -PA, para estudos futuros. O índice de diversidade utilizado foi o de Shannon Wiener $\left(\mathrm{H}^{\prime}\right)$. Este índice expressa a riqueza de uma amostra ou comunidade e assume que todas as espécies estão representadas, seu valor encontra-se entre 1,5 e 3,5; embora casos excepcionais possam exceder a 4,5 (REZENDE, 2002).

Os cálculos foram realizados com o BIO-DAP - Software para cálculos de Biodiversidade (MAGURRAN, 1988).

$\mathrm{Na}$ Tabela 1 estão listadas as espécies vegetais identificadas no quintal agroflorestal, assim como seus respectivos usos pela família.

Foram identificadas 36 (trinta e seis) espécies vegetais no total, sendo dezessete espécies frutíferas, sete hortaliças, seis medicinais, quatro ornamentais, uma cultivar e uma espécie madeireira.

As espécies frutíferas no quintal abrangeram $47 \%$ do total de plantas identificadas. O uso das frutíferas no estabelecimento se dá principalmente pelo consumo da própria família, a goiaba (Psidium guajava L.), a manga (Mangifera indica L.), o abacaxi (Ananas comosus (L.) Merr.) dentre outras frutas são utilizadas para consumo in natura, preparo de sucos naturais, preparo de chás, e doces, onde as frutas são amplamente aproveitadas desde a polpa, casca e até mesmo a semente, usada para o semeio de novas mudas. 
Tabela 1 - Espécies vegetais presentes no quintal agroflorestal e seus respectivos usos.

\begin{tabular}{|c|c|c|}
\hline Nome Vulgar & Nome Científico & Utilidade \\
\hline Abacaxi & Ananas comosus (L.) Merr. & Frutífera \\
\hline Abóbora & Cucurbita L. & Hortaliça \\
\hline Açaí & Euterpe oleracea Mart. & Frutífera \\
\hline Alfavaca & Ocimum basilicum $\mathrm{L}$. & Medicinal \\
\hline Banana & Musa spp. & Frutífera \\
\hline Boldo & Plectranthus barbatus Andrews & Medicinal \\
\hline Cacau & Theobroma cacao L. & Frutífera \\
\hline Caju & Anacardium occidentale $\mathrm{L}$. & Frutífera \\
\hline Carambola & Averrhoa carambola L. & Frutífera \\
\hline Cebolinha & Allium fistulosum L. & Hortaliça \\
\hline Coco & Cocos nucifera L. & Frutífera \\
\hline Comigo-ninguém-pode & Dieffenbachia amoena Bull. & Ornamental \\
\hline Copo-de-leite & Zantedeschia aethiopica (L.) Spreng. & Ornamental \\
\hline Couve & Brassica oleracea L. & Hortaliça \\
\hline Erva Cidreira & Melissa officinalis L. & Medicinal \\
\hline Goiaba & Psidium guajava $\mathrm{L}$. & Frutífera \\
\hline Graviola & Annona muricata $\mathrm{L}$. & Frutífera \\
\hline Gueroba & Syagrus oleracea Glassman & Frutífera \\
\hline Hortelã & Mentha L. & Medicinal \\
\hline Ipê & Tabebuia chrysotricha (Mart. ex A. DC.) Standl. & Madeireira \\
\hline Ixoria & Ixora coccinea $\mathrm{L}$. & Ornamental \\
\hline Jabuticaba & Myrciaria cauliflora (Mart.) O. Berg & Frutífera \\
\hline Jambo & Syzygium jambos (L.) Alston & Frutífera \\
\hline Jiló & Solanum gilo Raddi & Hortaliça \\
\hline Laranja & Citrus sinensis (L.) Osbeck & Frutífera \\
\hline Limão & Citrus aurantiifolia (Christm.) Swingle & Frutífera \\
\hline Macaxeira & Manihot esculenta Crantz & Cultivar \\
\hline Mamão & Carica papaya $\mathrm{L}$ & Frutífera \\
\hline Manga & Mangifera indica $\mathrm{L}$. & Frutífera \\
\hline Mastruz & Chenopodium ambrosioides L. & Medicinal \\
\hline Noni & Morinda citrifolia $\mathrm{L}$. & Medicinal \\
\hline Pepino & Cucumis sativus L. & Hortaliça \\
\hline Pimenta & Capsicum L. & Hortaliça \\
\hline Rosa & Rosa L. & Ornamental \\
\hline Tamarindo & Tamarindus indica $\mathrm{L}$. & Frutífera \\
\hline Tomate & Solanum lycopersicum L. & Hortaliça \\
\hline
\end{tabular}

Com os dados apresentados na Tabela 1 percebe-se claramente a maior quantidade de espécies frutíferas no lote (47\%) do total de plantas, seguida pelas hortaliças (19\%), medicinais (17\%), ornamentais $(11 \%)$, cultivar $(3 \%)$ e madeira também $(3 \%)$.

Em geral as espécies frutíferas representam $86,04 \%$ da população total amostrada, o que indica a preferência dos pequenos produtores pelo cultivo de frutíferas (FIGUEIREDO JÚNIOR et al., 2013). Estudando quatro quintais agroflorestais no município de Mazagão, no Amapá; Gazel Filho (2008) encontrou uma média de $(78 \%)$ de espécies frutíferas nos quintais estudados, neste mesmo trabalho o autor cita que verificou-se poucos exemplares de plantas medicinais e também ausência de ornamentais, 
diferentemente do que ocorre neste levantamento, onde apresenta-se tanto plantas medicinais quanto ornamentais, $(17 \%)$ e $(11 \%)$ respectivamente.

Estudos sobre a composição botânica e a estrutura dos quintais e das propriedades de suas espécies podem fornecer informações básicas para tomadas de decisões na aplicação de técnicas de intensificar e melhorar o manejo da terra ou conservação destes sítios. Ademais, propiciará às pessoas uma alimentação mais equilibrada e com menor dispêndio financeiro em adquiri-la fora da propriedade (GAZEL FILHO, 2008).

$\mathrm{O}$ uso de hortaliças pelos agricultores é exclusivamente para consumo próprio, seja no preparo de saladas com couve (Brassica oleracea L.), ou condimentos como pimenta (Capsicum L.). Cultivadas por suas belezas as plantas ornamentais são muito apreciadas pelos agricultores principalmente as rosas (Rosa L.).

Conforme observa-se mais claramente as plantas frutíferas são responsáveis por quase $50 \%$ de toda os indivíduos do quintal agroflorestal.

Segundo Lisboa et al. (2002) algumas espécies hortícolas são comuns nos quintais de pequenos produtores, tais como: Alfavaca (Ocimum basilicum L.), cebolinha (Allium fistulosum L.), chicória (Cichorium endivia L.), feijão (Phaseolus vulgaris L.), jerimum (Cucurbita pepo L.), mandioca (Manihot utilissima Pohl), macaxeira (Manihot esculenta Crantz), milho (Zea mays L.) e pimenta-de-cheiro (Capsicum brasilianum Clus).

A mandioca é cultivada em todas as regiões do Brasil, assumindo destacada importância na alimentação humana e animal, além de ser utilizada como matéria-prima em inúmeros produtos industriais (PEDRO; CUNHA:CARDOSO, 2013), um pequeno cultivo de mandioca no quintal agroflorestal é mantido pelo agricultor apenas para consumo da própria família.

O uso de espécies madeireiras não é feito pelo agricultor, devido ao número plantas se resumir a apenas uma, o Ipê (Tabebuia chrysotricha (Mart. ex A. DC.) Standl.) que é utilizado pelos agricultores apenas para sombreamento de frutíferas como o cacau (Theobroma cacao L.).

Todas as espécies vegetais presentes no quintal agroflorestal são consideradas importantes pelos agricultores, mas, duas destacam-se como sendo as mais utilizadas pela família, são elas: a banana (Musa spp) e a laranja (Citrus sinensis (L.) Osbeck), pois as mesmas são comercializadas pelos agricultores no próprio assentamento Alegria e geram uma renda extra para a família, além de contribuírem para a subsistência da família.

A Tabela 2 apresenta o índice Shannon-Wiener de diversidade de 
espécies para o quintal agroflorestal agrícola do P.A Alegria.

estudado no referido estabelecimento

Tabela 2 - Índice de Diversidade de Shannon-Wiener do quintal agroflorestal do estabelecimento estudado.

\begin{tabular}{lc}
\hline Área & Diversidade \\
\hline Quintal da propriedade estudada & 2,95 \\
\hline
\end{tabular}

O índice de diversidade de ShannonWiener encontrado para o local foi de 2,95 o que demonstra uma diversidade relativamente alta. Machado et al. (2005) estudando seis sistemas agroflorestais no Sul da Bahia encontrou índice de diversidade de Shannon-Wiener variando de 1,47 a 2,39. Em quatro quintais do município de Mazagão, no estado do Amapá; Gazel Filho (2008) obteve um índice médio de diversidade de aproximadamente 2,76 .

Gliessman (2001) aponta que ecossistemas naturais relativamente diversificados apresentam índice de diversidade de Shannon-Wiener entre 3 e 4. Pode-se notar então, que no quintal onde fora realizado este levantamento percebese uma diversidade relativamente alta se comparada a outros índices de diversidade de Shannon-Wiener encontrados nos trabalhos citados, ou seja, não podemos dizer que é uma diversidade alta, porém também não seria correto afirmar que o quintal agroflorestal em questão possui baixa diversidade de espécies.

Gomes (2010) enfatiza que questões socioeconômicas e culturais podem influenciar tanto na diversidade destes sistemas como na sua simplificação. Com esta afirmação percebe-se que fatores socioeconômicos contribuem para a diversidade dos quintais agroflorestais, pois trata-se de áreas pequenas, neste caso apenas um hectare, e em áreas dessas dimensões geralmente o objetivo da família é ter o maior número de espécies no quintal apenas para seu consumo. É justamente o que ocorre no quintal agroflorestal em questão, todas as espécies presentes na área do quintal são utilizadas apenas pela família de acordo com seu potencial de uso, com exceção apenas da banana e laranja que são comercializadas no próprio assentamento em pequena escala e esporadicamente.

Conclui-se que houve uma diversidade considerável de espécies vegetais de 
acordo com o índice de diversidade encontrado para o quintal agroflorestal, foram verificados também os diversos usos que a família faz das plantas presentes no local estudado. As espécies vegetais presentes no quintal contribuem tanto para a manutenção ecológica do quintal agroflorestal, quanto para o consumo da família e também colabora economicamente com a comercialização de frutos dentro do Assentamento.

\section{REFERÊNCIAS}

CASTRO, A. P.; FRAXE, T. J. P.; SANTIAGO, J. L.; MATOS, R. B.; PINTO, I. C. Os Sistemas Agroflorestais como Alternativa de Sustentabilidade em Ecossistemas de Várzea no Amazonas. Acta Amazônica, v. 39, n.2, p. 279-288, 2009.

FIGUEIREDO JÚNIOR, O. ; HAMADA, M.O.S.; SOUZA, S.P.O.; CORREA, R.F. Levantamento florístico dos quintais agroflorestais do PDS Virola jatobá em Anapú, Pará. Enciclopédia biosfera, Centro Científico Conhecer, Goiânia, v.9, n.17; p. 1793, 2011.

FRAXE, T. J. P.; CHAGAS, J. C. N.; VASQUES, M. S.; SANTIAGO, J. L.; ELIAS, M. E. A.; SOUSA, H. H. Importância dos Quintais Agroflorestais na Conservação de Plantas Aromáticas e Condimentares em Duas Comunidades de Várzea no Amazonas, 2012. In: ENCONTRO NACIONAL DA ANPPAS, 6., Belém, 2012. Anais... Belém: SBCS, 2012.

GAZEL FILHO, A. B. Composição, estrutura e função de quintais agroflorestais no Município de Mazagão, Amapá, Belém, 2008. 104 f. Tese (Doutorado em Ciências Agrárias) - Universidade Federal Rural da Amazônia, Embrapa Amazônia Oriental, Belém, 2008.
GLIESSMAN, S. R. Diversidade e estabilidade do agroecossistema. In: do Agroecologia: processos ecológicos em agricultura sustentável. Porto Alegre, Editora Universidade, 2001. p. 437-474.

GOMES, G. S. Quintais agroflorestais no município de Irati-Paraná, Brasil: agrobiodiversidade e sustentabilidade socioeconômica e ambiental. 2010. 143 f. Tese (Doutorado em Ciências Florestais)Universidade Federal do Paraná, Curitiba, 2010 .

LISBOA, P. L. B.; GOMES, I. A.; LISBOA, C. L.; URBINATI, C. V. O Estilo Amazônico de Sobreviver: Manejo dos Recursos Naturais. In: LISBOA, P. L (Org). Natureza, Homem e Manejo de Recursos Naturais na Região de Caxiuanã, Melgaço, Pará. Belém, PA: Museu Paraense Emílio Goeldi, 2002. p. 43-89.

MACHADO, E. L. M.; HIGASHIKAWA, E. M.; MACEDO, R. L. G.; VENTURIN, N.; NAVES, M. L.; GOMES, J. E. Análise da diversidade entre sistemas agroflorestais em assentamentos rurais no sul da Bahia. Revista Científica Eletrônica de Engenharia Florestal, Garça, v.5, n.1, p.1-14, 2005.

MAGURRAN, A. E. Ecological diversity and its measurement. Princeton: Princeton University Press, 1988.179 p.

PEDRO, L. P. M.; CUNHA, A. P. CARDOSO, E. L. M. Cultivo da Mandioca para o Estado do Pará. Disponível em: <http://sistemasdeproducao.cnptia.embrapa.br/ FontesHTML/Mandioca/mandioca_para/>.

Acesso em: 15 mar. 2013.

REZENDE, A. V. Diversidade, estrutura, dinâmica e prognose do crescimento de um cerrado senso stricto submetido a diferentes estudos por desmatamento. Curitiba, 2002.

243 f. Tese (Doutorado em engenharia florestal). Universidade Federal do Paraná, Curitiba, 2002. 